\title{
Different Morphology of ZnO Nanostructures Using Hydrothermal and Electro-Deposition Technique
}

\author{
Sarangi SN ${ }^{1 *}$, Acharya $\mathrm{S}^{2}$ and Biswal $\mathrm{SK}^{2}$ \\ ${ }^{1}$ Institute of Physics, PO- Sainik School, Sachivalaya Marg, Bhubaneswar-751005, India \\ ${ }^{2}$ Centurion University Of Technology \& Management, At-Ramchandrapur, PO-Jatni, Bhubaneswar, Dist: Khurda-752050, Odisha, India \\ *Corresponding author: Sarangi SN, Institute of Physics, P.O. Sainik School, Sachivalaya Marg, Bhubaneswar-751005, India

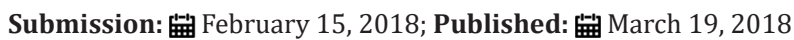

\section{Introduction}

The different morphology of $\mathrm{ZnO}$ material is possible by using hydrothermal synthesis and electro-chemical synthesis procedure. We have used zinc nitrate $\left(\mathrm{Zn}\left(\mathrm{NO}_{3}\right)_{2} \cdot 6 \mathrm{H}_{2} \mathrm{O}\right)$ and hexamethylenetetramine (HMT) $\left(\left(\mathrm{CH}_{2}\right)_{6} \mathrm{~N}_{4}\right)$ salts as starting material for synthesis of $\mathrm{ZnO}$ hydrothermal synthesis and electrochemical synthesis procedure. The field emission scanning electron microscopy (FESEM) techniques was used to observe the effect of precursor variation in hydrothermal technique and deposition time period in electrochemical technique on the morphology of the $\mathrm{ZnO}$ nanostructures.

One-dimensional semiconductor nanostructures such as nanorods, nanowires, nanosheets, and nanotubes have attracted much attention due to their unique properties which is useful for various applications [1,2]. Zinc oxide ( $\mathrm{ZnO}$ ) has been widely studied because of its unique properties and applications in the field of optoelectronics, photo detector, photo catalysis, sensors and nanotechnology [1-7]. Solution phase methods have been used to synthesize $\mathrm{ZnO}$ nanostructures because of their popular chemical procedure and its simplicity which is carried out at ambient or slightly elevated temperature. Hydrothermal growth technique and electrochemical techniques are found to be a simple and cost-effective technique for preparing $\mathrm{ZnO}$ materials nanorods [1,2]. In the present work, $\mathrm{ZnO}$ materials of different morphology were prepared by hydrothermal growth technique and electro-deposition technique and the morphology of the $\mathrm{ZnO}$ nanostructures/macrostructure have been investigated.

We have already published the synthesis of $\mathrm{ZnO}$ via hydrothermal technique [1] and electro-deposition technique [2]. Two samples of precursor concentrations $10 \mathrm{mM}$ and $500 \mathrm{mM}$ prepared using hydrothermal methods, renamed as $10 \mathrm{mM}-\mathrm{S} 1$ and $500 \mathrm{mM}-\mathrm{S} 2$ and two other samples were prepared using electrodeposition technique for 5 minutes and 20 minutes deposition period were renamed as S3 and S4 respectively. The morphology of samples was investigated by field-emission scanning electron microscopy (FESEM).

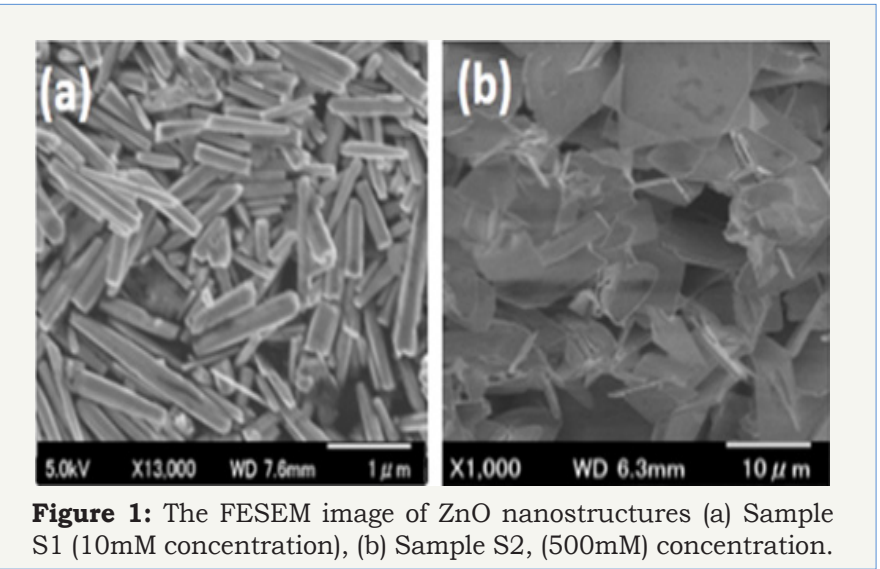

Figure 1 shows the FESEM images of $\mathrm{ZnO}$ materials and the effects of precursor concentration on the morphology of $\mathrm{ZnO}$. Figure 1 (a) shows the morphology of sample S1 where the precursor concentration was chosen to be $10 \mathrm{mM}$. The length of the nanorods found to be more than $2.0 \mu \mathrm{m}$ and the diameter of the $\mathrm{ZnO}$ nanorods are in the range of 60 to $80 \mathrm{~nm}$. Similarly, Figure 1 (b) shows the morphology of sample S2 where the precursor concentration was chosen to be $500 \mathrm{mM}$ and the micrograph shows, instead of nanorods, macro structure/ thin film like morphology was observed. The increase in precursor concentration increases the availability of nucleation center on the surface of the substrate thus induces different morphology.

Figure 2 (a) shows the morphology of sample S3 where the electro-deposition time was set for 5 minutes and Figure 2(b) shows the morphology of sample S4where the deposition time was set for 20 minutes. This result suggests that, with increase in electro-deposition duration, the rate of growth of $\mathrm{ZnO}$ nanorodson ITO substrate can be increased. 
In conclusion, tuning in morphology of $\mathrm{ZnO}$ material is possible using hydrothermal and electro-deposition technique by varying the precursor concentration and electro-deposition time respectively.
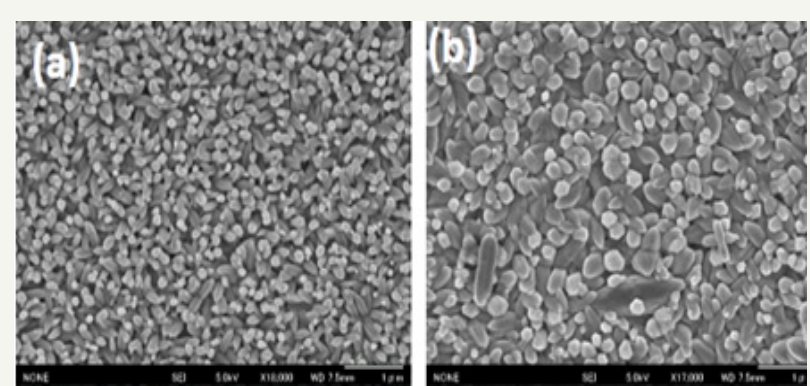

Figure 2: The FESEM image of $\mathrm{ZnO}$ nanostructures (a) Sample S3 (5min), (b) Sample S4, (20min) duration.

\section{References}

1. Sarangi SN, Nozaki S, Sahu SN (2015) ZnO nanorod-based non-enzymatic optical glucose biosensor. J Biomed Nanotech11 (6): 988-996.
2. SN Sarangi (2016) Controllable growth of $\mathrm{ZnO}$ nanorods via electrode position technique: towards UV photo-detection. Journal of Physics D: Applied Physics 49 (35): 355103.

3. Chen H, Zhao L, Wang G, Fang W (2017) Direct growth of ZnO nanorods on biogenic hierarchical rice husk $\mathrm{SiO}_{2}$ and their application to dye degradation, Clean Techn Environ Policy, 19(5): 1335-1345.

4. Zhao Y, Yu N, Dong X, Yan H (2017) Large area growth of ZnO Nanorods arrays on the stainless steel grid by aqueous solutions, Materials Research Innovations, 21(7): 447-450.

5. Husham M, Nizar MH, Paiman S, Abuelsamen AA, Farhat OF, et al (2017) Synthesis of ZnO nanorods by microwave-assisted chemical-bath deposition for highly sensitive self-powered UV detection application. Sensor Act A 263: 166-173.

6. Jeem M, Zhang L, Ishioka J, Shibayama T, Iwasaki T, et al. (2017) Tuning optoelectrical properties of $\mathrm{ZnO}$ nanorods with excitonicdefects via submerged illumination. Nano Lett 17(3): 2088-2093.

7. Tiwari S, Vinchurkar M, Rao VR, Garnier G (2017) Zinc oxide nanorods functionalized paper for protein pre-concentration in bio diagnostics. Sci Rep 7: 43905 .

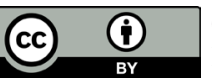

reative Commons Attribution 4.0 International License

For possible submissions Click Here

\section{Submit Article}

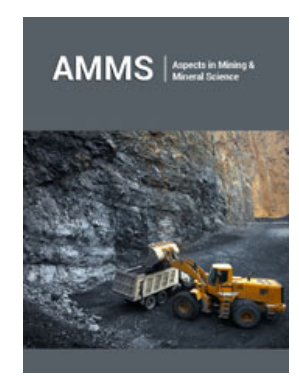

\section{Aspects in Mining \& Mineral Science}

\section{Benefits of Publishing with us}

- High-level peer review and editorial services

- Freely accessible online immediately upon publication

- Authors retain the copyright to their work

- Licensing it under a Creative Commons license

- Visibility through different online platforms 